\title{
SP600125, a selective JNK inhibitor, aggravates hepatic ischemia-reperfusion injury
}

\author{
Kyung-Hoon Lee ${ }^{1,2}$, Sang-Eun Kim ${ }^{1}$ and \\ Yun-Song Lee ${ }^{1,3}$ \\ ${ }^{1}$ Department of Molecular and Cellular Biology \\ Sungkyunkwan University School of Medicine \\ Suwon 440-746, Korea \\ ${ }^{2}$ Clinical Trial Center \\ Clinical Research Institute \\ Samsung Medical Center \\ Seoul 135-710, Korea \\ ${ }^{3}$ Corresponding author: Tel, 82-31-299-6190; \\ Fax, 82-31-299-6209; E-mail, yslee@skku.edu
}

Accepted 7 July 2006

Abbreviations: ALT, serum alanine aminotransferase; I/R, ischemiareperfusion; JNK, c-Jun $N$-terminal kinase; MAPK, mitogen-activated protein kinase; MDA, malondialdehyde; MIP, macrophage inflammatory protein; MMP, matrix metalloproteinase; MPO, myeloperoxidase; ROS, reactive oxygen species; RPA, ribonuclease protection assay

\begin{abstract}
c-Jun $\mathbf{N}$-terminal kinase (JNK) is activated during hepatic reperfusion, and JNK inhibitors are known to protect other major organs from ischemia-reperfusion (I/R) injury. We attempted to determine the effect of SP600125, a JNK inhibitor, on hepatic I/R injury using a partial ischemia model in mice. Compared to a vehicle-treated group, the SP600125treated group showed a greater increase in serum ALT levels $24 \mathrm{~h}$ after reperfusion with more severe parenchymal destruction and leukocyte infiltration. Similarly, tissue myeloperoxidase and malondialdehyde levels were higher in the SP600125-treated group, and chemokine expression was also higher in the SP600125-treated group. These data, which are contradictory to previous results, indicate that JNK inhibition by SP600125 may be harmful in hepatic I/R injury. Therefore, care must be taken when inves tigating the therapeutic use of JNK inhibitors in hepatic I/R injury, especially in the context of the effects of JNK inhibition on inflammatory infiltration.
\end{abstract}

Keywords: anthra(1,9-cd)pyrazol-6(2H)-one; ischemia; JNK mitogen-activated protein kinases; liver; reperfusion injury

\section{Introduction}

Ischemia-reperfusion (I/R) injury is an important problem in clinical situations such as liver transplantation, hepatic resectional surgery, and circulatory shock. Hepatic I/R injury causes apoptosis and necrosis in the liver (Jaeschke \& Lemasters, 2003a), which can lead to liver failure and/or multiple organ failure, resulting in an increase in morbidity and mortality. The related cellular injury is caused by a complex of inflammatory processes, including activation of Kupffer cells (Matsumura et al., 1998), generation of reactive oxygen species (ROS) (Fernandez et al., 2002), liberation of cytokines/ chemokines and leukocyte infiltration (Takeuchi et al., 2004; Zhai et al., 2004), and release of degrading enzymes such as matrix metalloproteinases (MMPs) (Cursio et al., 2001).

C-Jun $N$-terminal kinase (JNK) is one of the signaling molecules activated in hepatic I/R injury (Onishi et al., 1997; Zwacka et al., 1998). JNK is activated by environmental stresses such as oxidative stress (Mendelson et al., 1996), and also by cytokines, including TNF- $\alpha$ (Liedtke et al., 2002) and IL-1 (Finch et al., 2001). These cytokines are considered to be major mediators in hepatic I/R injury (Kato et al., 2002; Teoh et al., 2004). JNK activation during reperfusion is believed to play a role in hepatocyte apoptosis (Marderstein et al., 2003; Uehara et al., 2004; Uehara et al., 2005). JNK also mediates inflammatory processes by inducing the expression of adhesion molecules (Miho et al., 2005) and inflammatory chemokines/cytokines (Paik et al., 2003; Arndt et al., 2004). Therefore, JNK is thought to play a key role in hepatic I/R injury.

SP600125, a reversible ATP-competitive inhibitor, selectively inhibits JNK activity (Bennett et al., 2001), reduces ischemia-reperfusion injury in the brain (Gao et al., 2005) and the lungs (Ishii et al., 2004), and protects hepatocytes from apoptosis due to TNF- $\alpha$ (Marderstein et al., 2003). Therefore, we attempted to determine whether SP600125 attenuates hepatic $\mathrm{I} / \mathrm{R}$ injury in vivo using a partial hepatic I/R model in mice.

\section{Materials and Methods}

\section{Reagents}

SP600125 (Alexis Biochemicals, San Diego, CA) 
was dissolved in a vehicle (30\% PEG-400/20\% polypropylene glycol/15\% Cremophor EL/5\% ethanol/ $30 \%$ saline) at a concentration of $2 \mathrm{mg} / \mathrm{ml}$ (Bennett et al., 2001). Multiple probes for expression of chemokines and MMPs, and an RPA kit were obtained from Pharmingen (San Diego, CA). All antibodies were obtained from Cell Signaling Technology (Beverly, MA), except anti- $\beta$-actin antibody (Sigma, St. Louis, MO). All other chemicals were purchased from Sigma.

\section{Induction of partial hepatic I/R injury}

Animal experiments were approved by the Panel on Laboratory Animal Care and Use of Sungkyunkwan University School of Medicine. Male C57BL/6 mice weighing 25 to $30 \mathrm{~g}$ (Orient, Korea) were allowed free access to food and water before and after hepatic I/R. Six mice in each group were subjected to partial hepatic I/R procedures, as described previously (Kato et al., 2002) with slight modification. In brief, mice were anesthetized by enflurane inhalation using a nose cone. After a midline laparotomy, heparin $(100 \mathrm{U} / \mathrm{kg}$ ) was administered via a tail vein. The portal triad to the left and median hepatic lobes was occluded with a microclamp (Fine Science Tools, Foster City, CA) for $60 \mathrm{~min}$. At the onset of ischemia, SP600125 was administered in the intraperitoneal space at a dose of $10 \mathrm{mg} / \mathrm{kg}$, and the abdominal wall was temporarily sutured. The vehicle was administered at the same volume per $\mathrm{kg}$ of body weight. During the ischemic period, mice were kept anesthetized with enflurane. Reperfusion was induced by release of the microclamp, and SP600125 was subcutaneously administered in the right inner thigh area at the same dose $(10 \mathrm{mg} / \mathrm{kg})$. The peritoneal/muscular and skin abdominal layers were separately sutured with 5-0 black silk, and the mice were allowed to recover by discontinuation of the enflurane. During the procedures, mice were kept warm with a heating pad and a lamp to prevent hypothermia, and $0.2 \mathrm{ml}$ of PBS was subcutaneously injected to prevent hypovolemia. Mice were euthanized with enflurane, blood was drawn from the right cardiac ventricle, and hepatic tissue was obtained for histology and biochemistry assays.

\section{Histological examination}

Liver slices from the middle of the median lobe were fixed in Bouin's solution (Sigma) and embedded in paraffin. Sections of $5 \mu \mathrm{m}$ were stained with hematoxylin and eosin.

\section{Serum ALT assay}

Serum alanine aminotransferase (ALT) levels were measured with a kit (Sigma) according to the in- structions of the manufacturer. Serum ALT levels were expressed in Sigma-Frankel U/ml of serum.

\section{Determination of malondialdehyde (MDA) levels}

Tissue MDA levels were used as an oxidative damage index. Values were determined using a commercial kit (Calbiochem, San Diego, CA) according to the instructions of the manufacturer.

\section{Immunoblot analysis}

Pieces of the median and left lobes that were subjected to I/R were homogenized in a buffer (20 $\mathrm{mM}$ Tris, $\mathrm{pH}$ 7.5, $150 \mathrm{mM} \mathrm{NaCl}, 1 \mathrm{mM}$ EDTA, $1 \mathrm{mM}$ EGTA, 1\% Triton $\mathrm{X}-100,2.5 \mathrm{mM}$ sodium pyrophosphate, $1 \mathrm{mM} \beta$-glycerophosphate, $1 \mathrm{mM}$ sodium orthovanadate, $2 \mathrm{mM}$ PNPP, $1 \mu \mathrm{g} / \mathrm{ml}$ aprotinin, 1 $\mu \mathrm{g} / \mathrm{ml}$ leupeptin, $1 \mathrm{mM}$ PMSF, and $2 \mu \mathrm{g} / \mathrm{ml}$ pepstatin) using a mechanical homogenizer (Brinkmann Instruments, Westbury, NY). Homogenates were centrifuged at $14,000 \mathrm{~g}$ for $20 \mathrm{~min}$, and the supernatants were collected. After determination of protein concentrations using a kit (BioRad, Hercules, CA) with BSA as a standard, proteins $(50 \mu \mathrm{g})$ were separated in $12 \%$ SDS-PAGE gel and transferred to PVDF membranes (Schleicher \& Schuell, Keene, NH). Membranes were blocked with $5 \%$ skim milk in T-TBS $(0.1 \%$ Tween-20 in Tris-buffered saline; $8 \mathrm{~g} / \mathrm{l}$ $\mathrm{NaCl}, 3 \mathrm{~g} / \mathrm{l}$ Tris, $\mathrm{pH}$ 7.4) at room temperature for 1 $\mathrm{hr}$, then the membranes were incubated overnight at $4^{\circ} \mathrm{C}$ with either the primary antibody to p-cJun, $p$ JNK, $p$-p38, or $p$-ERK at a titer of $1: 1,000$, or with anti- $\beta$-actin antibody at a titer of $1: 25,000$. Membranes were washed with T-TBS and proteins were detected using ECL reagents (Amersham, Piscataway, NJ) and a chemiluminescence detector (Fuji, Japan).

\section{Determination of matrix metalloproteinase-9 (MMP-9) activity}

Tissue MMP-9 activities were determined by gelatin zymography (Cursio et al., 2001). In brief, approximately $100 \mathrm{mg}$ of liver tissue was homogenized with $1 \mathrm{ml}$ of an extraction buffer (50 mM Tris-Cl, $\mathrm{pH} 7.4$, $20 \mathrm{mM} \mathrm{NaCl}$, and a protease inhibitor cocktail (Sigma)). Tissue homogenates were centrifuged at $16,000 \mathrm{~g}$ for $30 \mathrm{~min}$ at $4^{\circ} \mathrm{C}$, then the supernatants were collected. After $100 \mu \mathrm{g}$ of protein was separated in $10 \%$ SDS-PAGE gel containing $1 \%$ gelatin (Sigma), the gel was washed twice with a washing solution (50 mM Tris-Cl, $\mathrm{pH} 7.4$, and $2.5 \%$ Triton $\mathrm{X}-100)$ for $30 \mathrm{~min}$, and once with a developing solution (50 mM Tris- $\mathrm{Cl}, \mathrm{pH} 7.4,10 \mathrm{mM} \mathrm{CaCl}_{2}$, and 5 $\mu \mathrm{M} \mathrm{ZnCl}_{2}$ ). After incubation in a developing solution at $37^{\circ} \mathrm{C}$ for $24 \mathrm{~h}$ with gentle shaking, the gel was 
washed with a fixing solution (40\% methanol and $10 \%$ acetic acid) and stained with $0.1 \%$ Coomassie Blue R 250 in the fixing solution for $30 \mathrm{~min}$ at room temperature. The gel was subsequently destained in the fixing solution for $30 \mathrm{~min}$. Volumetric analysis of MMP-9 activity was performed using imaging software (Fuji).

\section{Tissue myeloperoxidase (MPO) assay}

For determining neutrophil infiltration, the MPO activity was measured by the tetramethylbenzidine (TMB) method (Schierwagen et al., 1990). In brief, liver tissue was homogenized in $20 \mathrm{mM}$ sodium phosphate at $\mathrm{pH}$ 7.4. After centrifugation at $10,000 \mathrm{~g}$ at $4^{\circ} \mathrm{C}$ for $5 \mathrm{~min}$, pellets were suspended with $0.5 \%$ hexadecyl trimethylammonium bromide in $50 \mathrm{mM}$ potassium phosphate at pH 6.0. Suspended pellets were snap-frozen in liquid nitrogen and consecutively thawed three times. The pellets were sonicated for $30 \mathrm{~s}$, incubated at $60^{\circ} \mathrm{C}$ for $2 \mathrm{~h}$, and centrifuged at $10,000 \mathrm{~g}$ at $4^{\circ} \mathrm{C}$ for $5 \mathrm{~min}$. Supernatants $(75 \mu \mathrm{l})$ were added to $675 \mu$ of a reaction mixture $(0.16 \mathrm{mM}$ TMB, $0.24 \mathrm{mM} \mathrm{H}_{2} \mathrm{O}_{2}$, and $80 \mathrm{mM}$ potassium phosphate, $\mathrm{pH}$ 5.4). The change in absorbance at $655 \mathrm{~nm}$ at $37^{\circ} \mathrm{C}$ was measured using a spectrophotometer (Agilent Technologies, Wilmington, DE). One unit was defined as the amount of activity required to produce an increase of 1 absorbance unit per min, and the specific activity was expressed as the activity per $\mathrm{mg}$ of protein.

\section{Ribonuclease protection assay (RPA)}

To determine the expressions of chemokine and MMP genes, RPA was performed with multiple probe sets (mCK-5C and mMMP-1) and an RPA kit according to the instructions of the manufacturer. Total RNAs were isolated with a kit (Sigma). In vitro transcription and labeling of probes with $\alpha-\left[{ }^{32} \mathrm{P}\right]-\mathrm{UTP}$ (Amersham) were performed with a kit (Pharmingen) according to the instructions of the manufacturer. After hybridization and digestion with RNases, protected RNA fragments were separated in 5\% $8 \mathrm{M}$ urea PAGE gel and visualized using a phosphoimager (Fuji).

\section{Statistical analysis}

Data are presented as mean \pm SE. Data were analyzed by ANOVA with a multiple comparison test to detect whether SP600125 had a significant effect on hepatic I/R injury. The statistical significance was set at $P<0.05$.

\section{Results}

\section{SP600125 inhibits JNK activation in I/R liver}

SP600125 selectively inhibits JNK in a competitive manner. Therefore, the inhibitory effect of SP600125 on JNK activity was indirectly validated by a decrease observed in the phosphorylation level of the JNK substrate c-Jun in hepatic tissues of SP600125-treated mice in comparison with vehicletreated mice (Figure 1). While the phosphorylation level of c-Jun at Ser63 was increased 15 min and 1 $\mathrm{h}$ after reperfusion in the vehicle-treated group, SP600125 treatment inhibited induction of c-Jun phosphorylation at $15 \mathrm{~min}$ and $1 \mathrm{~h}$. However, SP600125 did not inhibit reperfusion-induced phosphorylation of MAPKs, including JNK, p38 MAPK, and ERK. This indicates that SP600125 selectively inhibits JNK kinase activity in liver tissue subjected to I/R.

\section{SP600125 aggravates hepatic I/R injury}

Serum ALT levels were measured in order to evaluate the effects of SP600125 on I/R-induced liver damage. Non-operated, vehicle sham-operated, and SP600125 sham-operated groups did not show any significant differences in serum ALT levels $24 \mathrm{~h}$ after operation (Figure 2A). Following $60 \mathrm{~min}$ of partial ischemia, reperfusion significantly increased serum ALT levels in the vehicle-treated I/R group

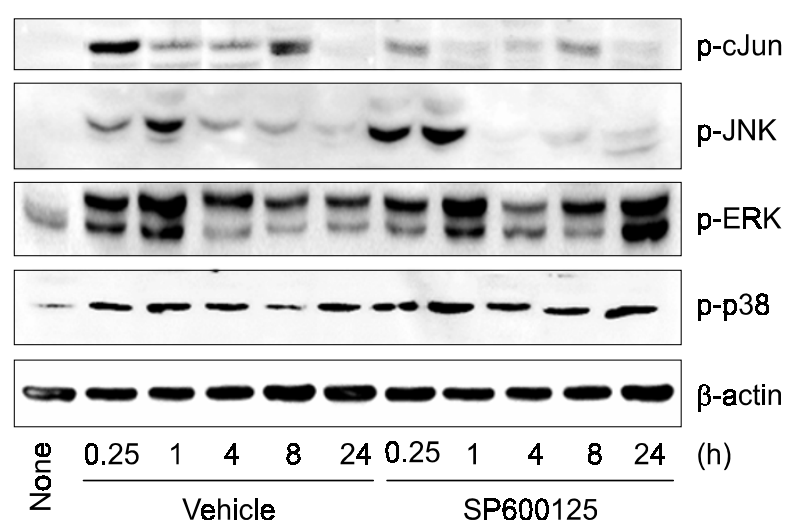

Figure 1. Selective inhibition of c-Jun phosphorylation (Ser63) by SP600125. Partial ischemia was induced by clamping of the portal triad leading to the median and left lobes of the liver for $60 \mathrm{~min}$. The lobes were reperfused by release of the clamp. Vehicle or SP600125 treatment was administered to mice at the onset of both ischemia (intraperitoneal) and reperfusion (subcutaneous). At the indicated times after reperfusion, the liver was removed to determine the phosphorylation status of c-Jun and MAPKs using immunoblot analysis. Proteins $(50 \mu \mathrm{g})$ were separated in $12 \%$ SDS-PAGE gel and transferred to PVDF membranes. Immunoblot analysis was performed using phospho-specific antibodies, as described in "Materials and Methods". 
A

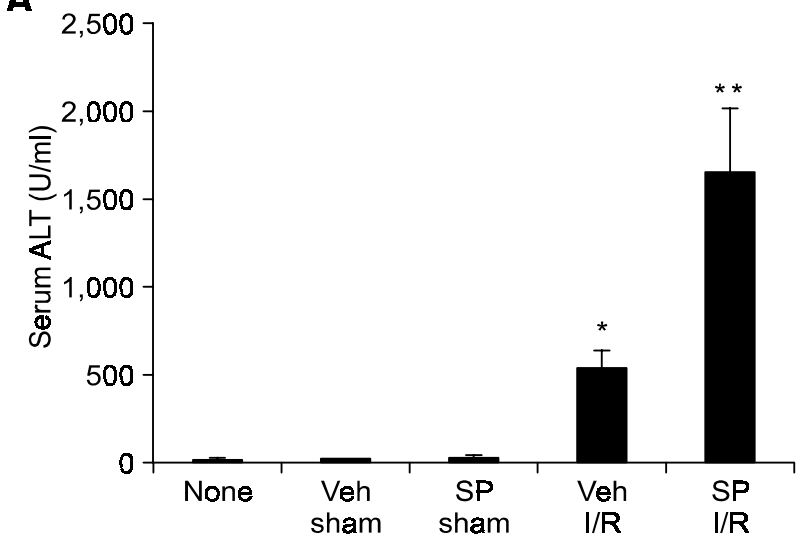

B

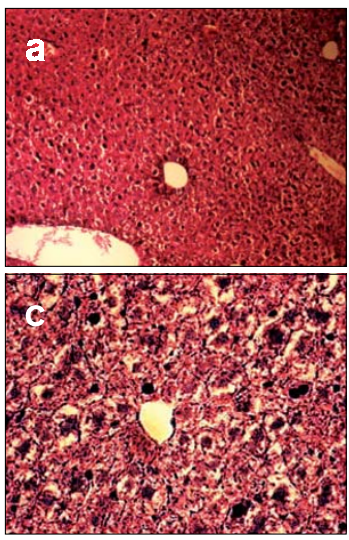

Vehicle

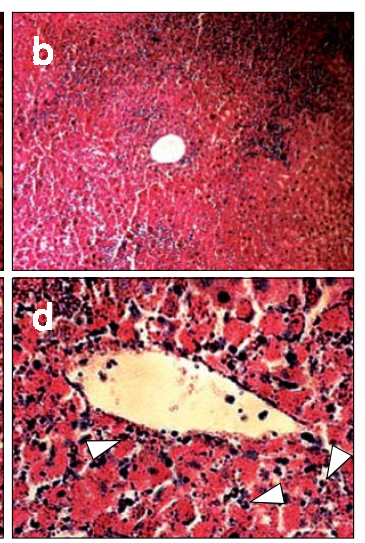

SP600125

Figure 2. Aggravation of hepatic ischemia-reperfusion (I/R) injury by SP600125. (A) SP600125 causes a greater increase in serum ALT levels $24 \mathrm{~h}$ after reperfusion than vehicle treatment. None, Veh Sham, SP Sham, Veh I/R, or SP I/R indicate no surgical operation, vehicle administration with sham operation, SP600125 administration with sham operation, vehicle administration with I/R operation, and SP600125 administration with I/R operation, respectively. Data are expressed as mean $\pm \mathrm{SE}(n=6)$, and asterisks indicate a statistical difference $\left(P<0.05 ;{ }^{*}\right.$ None vs. Veh I/R; ${ }^{* *}$ Veh I/R vs. SP I/R). (B) SP600125 augments histological liver injury $24 \mathrm{~h}$ after reperfusion. Liver sections $(5 \mu \mathrm{m})$ of vehicle-treated (a, c) and SP600127-treated $(b, d)$ I/R groups $24 \mathrm{~h}$ after reperfusion were stained with $\mathrm{H} \& \mathrm{E}$. The samples were observed at $\times 100(\mathrm{a}, \mathrm{b})$ and $\times 400(\mathrm{c}, \mathrm{d})$ magnification. Arrowheads indicate infiltrated leukocytes.

$(538 \pm 95 \mathrm{U} / \mathrm{ml}$, mean $\pm \mathrm{SE})$ in comparison with the non-operated, vehicle-treated sham-operated, and SP600125-treated sham-operated groups. SP600125 caused an increase in serum ALT levels to a much greater extent $(1,649 \pm 362 \mathrm{U} / \mathrm{ml})$ than did the vehicle treatment in mice subjected to $I / R$ (Figure 2A). SP600125, however, did not cause an increase in serum ALT levels at either $4 \mathrm{~h}$ (vehicle, 13,581 \pm $2,245 \mathrm{U} / \mathrm{ml}$; SP600125, 12,928 $\pm 3,746 \mathrm{U} / \mathrm{ml}$ ) or $8 \mathrm{~h}$ (vehicle, 6,732 $\pm 1,939 \mathrm{U} / \mathrm{ml}$; SP600125, 10,342 \pm $1,760 \mathrm{U} / \mathrm{ml})$.

Similar to the effect on serum ALT levels, SP600125 led to worsening in liver histology $24 \mathrm{~h}$ after reperfusion. In Figure 2B, the reperfused liver lobes in the vehicle-treated I/R group show pathological changes, including destruction of the hepatic cord, pericentral necrosis, vacuolarization of hepatocytes, and mild leukocyte infiltration. In the SP600125treated I/R group, more extensive hepatic necrosis was accompanied by more intense leukocyte infiltration than in the vehicle-treated group. Consistent with more intense leukocyte infiltration, higher MPO activities were observed in the SP600125-treated I/R group $(1.76 \pm 0.61 \mathrm{U} / \mathrm{mg}$ protein) than in the vehicletreated I/R group $(0.24 \pm 0.12) 24 \mathrm{~h}$ after reperfusion. There was no significant difference between the two groups 4 and $8 \mathrm{~h}$ following reperfusion (Figure 3 ).

\section{SP600125 increases chemokine expression}

Histological examination and an MPO assay showed more extensive neutrophil infiltration in the SP600125-

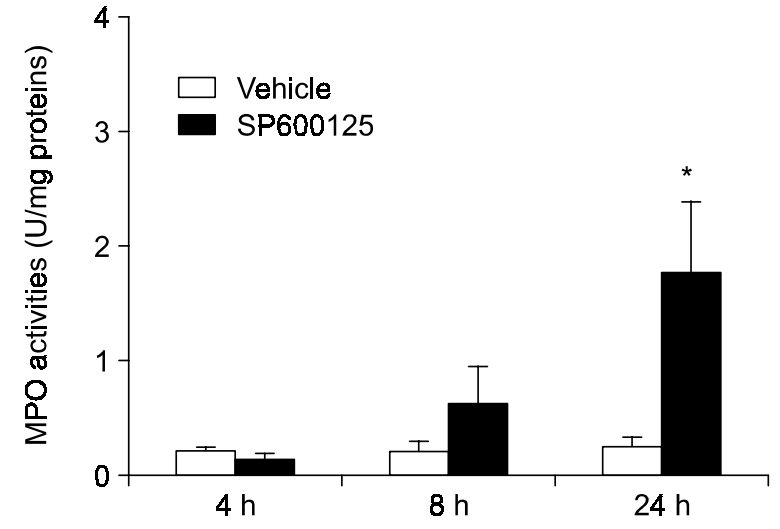

Figure 3. SP600125 increases neutrophil infiltration in reperfused liver tissue. To confirm neutrophil infiltration on histological examination, the activity of myeloperoxidase (MPO), a marker enzyme of neutrophils, was determined at the indicated times after reperfusion. Specific MPO activities are denoted as $U$ per $\mathrm{mg}$ protein. Data are expressed as mean \pm SE $(n=6)$, and an asterisk $\left(^{*}\right)$ indicates a statistical difference between vehicle-treated and SP600125-treated I/R groups $(P<$ 0.05).

treated group $24 \mathrm{~h}$ after reperfusion (Figure 2 and Figure 3). We therefore determined the effect of SP600125 on expression of the chemokines required for neutrophil recruitment. RPA assay results showed that SP600125 caused more intense expression of MIP-1 $\alpha$, MIP-1 $\beta$, and MIP-2 $8 \mathrm{~h}$ after reperfusion (Figure 4). However, there was no significant difference in chemokine gene expression between the two groups $4 \mathrm{~h}$ or $24 \mathrm{~h}$ after reperfusion. 


\section{SP600125 augments oxidative stress}

During hepatic reperfusion, ROS are generated mainly from Kupffer cells and infiltrating leukocytes (Jaeschke et al., 2003b). Since ROS are thought to induce cell death in hepatic I/R injury (Zhao et al., 2004) and lipid peroxidation products generated by ROS act as chemoattractants (Schaur et al., 1994), we estimated the effect of SP600125 on ROS generation and oxidative stress to the liver during hepatic I/R by measuring the malondialdehye (MDA) levels. MDA levels were significantly higher in the SP600125-treated group $(6.91 \pm 0.84 \mathrm{nM} / \mathrm{mg}$ proteins) than in the vehicle-treated group (4.84 \pm 0.41 $\mathrm{nM} / \mathrm{mg}$ proteins) $24 \mathrm{~h}$ after reperfusion, whereas there was no significant difference between two groups $4 \mathrm{~h}$ or $8 \mathrm{~h}$ after reperfusion (Figure 5). This indicates that SP600125 may have little effect on ROS generation in the early phase when Kupffer cells act as the major source of ROS (Jaeschke et

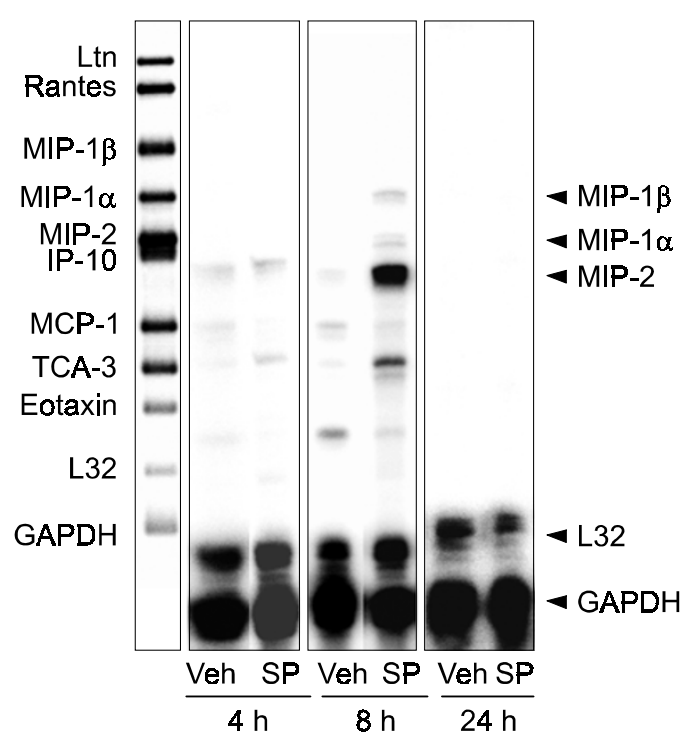

al., 2003b). Instead, SP600125 seems to augment oxidative stress mainly through amplification of neutrophil infiltration in a later phase because the increase in MDA levels coincided with the increase in neutrophil infiltration $24 \mathrm{~h}$ after reperfusion.

\section{SP600125 causes greater induction of MMP-9 activity}

MMP inhibitors reduced hepatic damage in hepatic $\mathrm{I} / \mathrm{R}$ injury (Cursio et al., 2001) and SP600125 inhibited MMP-9 induction (Shin et al., 2002), so the effect of SP600125 on MMP-9 was determined in liver tissues. While MMP-9 activity was hardly detected in the group with no operation, reperfusion increased MMP-9 gelatinolytic activity in the vehicletreated group (Figure 6A). However, contrary to the findings of a previous report (Shin et al., 2002), SP600125 did not reduce MMP-9 activity in liver tissues, but did increase MMP-9 activity to a significantly greater extent $8 \mathrm{~h}$ after reperfusion. Consistent with the effect of SP600125 on MMP-9 activity, SP 600125 led to a greater induction of MMP-9 and MMP-8 mRNA expression $8 \mathrm{~h}$ after reperfusion (Figure 6B).

\section{Discussion}

Several intracellular signaling pathways, including NF-kB (Fan et al., 2004), p38 MAPK (Kobayashi et al., 2002), and JNK (Bradham et al., 1997; Onishi et al., 1997) are activated in hepatic I/R injury. The activation of signaling pathways is believed to evoke complicated inflammatory processes and cell death. Therefore, relevant signaling pathways are potential therapeutic targets. For example, the attenuation of hepatic I/R injury by a p38 MAPK inhibitor identifies p38 MAPK as a therapeutic target in I/R injury (Kobayashi et al., 2002). JNK has also been suggested as a therapeutic target in reperfusion injury of
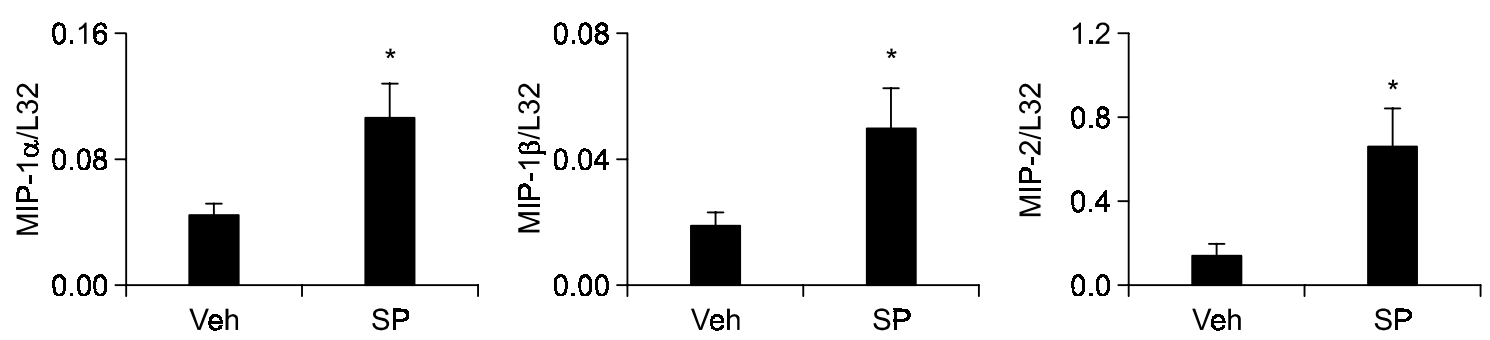

Figure 4. SP600125 enhances chomokine expression in reperfused liver tissue. To determine chemokine mRNA expression, a ribonuclease protection assay (RPA) was performed with total RNAs $(20 \mu \mathrm{g})$ and radiolabeled multiple chemokine RNA probes. Protected RNA fragments were separated in 5\% $8 \mathrm{M}$ urea PAGE gel and detected using a phosphoimager. (A) Images of protected RNA fragments. Undigested RNA probes are shown in the first lane. The following lanes show patterns of digested RNA fragments, i.e. expression of each chemokine gene, 4, 8, and $24 \mathrm{~h}$ after reperfusion. Veh or SP indicates the vehicle-treated and SP600125-treated I/R group, respectively. (B) Quantitative results of chemokine gene expression $8 \mathrm{~h}$ after reperfusion. Relative band intensities of each chemokine to $\mathrm{L} 32$ were quantified, and data are expressed as mean $\pm \mathrm{SE}(n=6)$. An asterisk $\left(^{*}\right)$ indicates a statistical difference between vehicle-treated and SP600125-treated I/R groups $(P<0.05)$. 


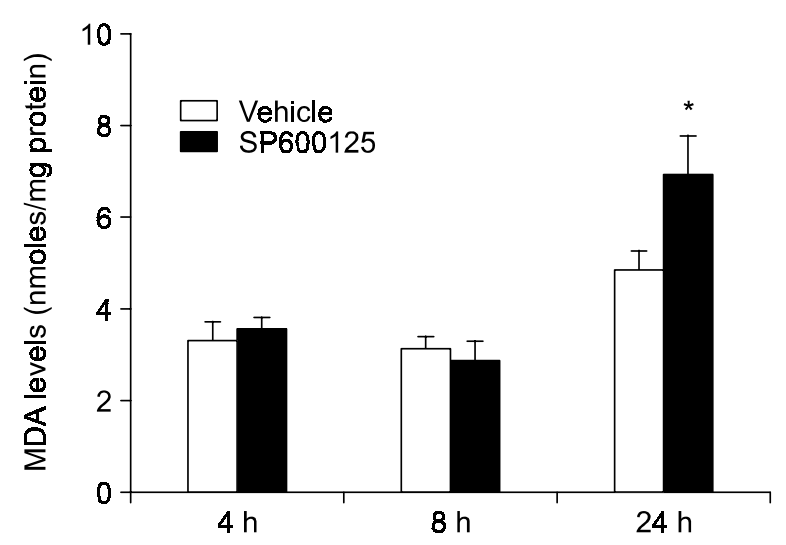

Figure 5. SP600125 increases lipid peroxidation. At 4, 8, and $24 \mathrm{~h}$ after reperfusion, malondialdehyde (MDA) levels were measured in liver tissue from the vehicle-treated and SP600125-treated I/R groups. MDA contents are expressed as nmoles of MDA/mg protein. Data are expressed as mean $\pm \operatorname{SE}(n=6)$, and an asterisk $\left({ }^{*}\right)$ indicates a statistical difference between the vehicle-treated I/R and SP600125-treated I/R groups $(P<0.05)$.

major organs, such as the brain (Gao et al., 2005) and the lung (Ishii et al., 2004) because it was found that chemical JNK inhibitors attenuate reperfusion injury in these organs.

Uehara et al., (2005) recently reported that several novel JNK inhibitors successfully attenuated hepatic $\mathrm{I} / \mathrm{R}$ injury and increased the survival rate of rats subjected to partial hepatic $I / R$ and resectioning of the remaining non-ischemic lobes. In contrast to our results, the novel JNK inhibitors that were used in the Uehara study inhibited hepatocyte death, an increase in the serum ALT level, neutrophil infiltration, and tissue lipid peroxidation. Even though we did not compare the effects of SP600125 and their JNK inhibitors in our model, our results consistently showed harmful effects of SP600125 administration in hepatic I/R injury.

In our regimen of SP600125 administration, SP600125 inhibited c-Jun phosphorylation in the early phase of reperfusion without producing an effect on MAPK phosphorylation, which indicates selective inhibition of JNK activity by SP600125. Additionally, SP600125 augmented chemokine gene expression $8 \mathrm{~h}$ after reperfusion followed by more extensive neutrophil infiltration, a higher serum ALT level, and a tissue MDA level with exaggerated histological injury $24 \mathrm{~h}$ after reperfusion. SP600125 did not affect serum ALT levels, neutrophil infiltration, or lipid peroxidation 4 and $8 \mathrm{~h}$ after reperfusion when compared with the vehicle treatment. Therefore, the effect of SP600125 on liver injury may account for part of the increase in the expression of chemokine genes, subsequent recruitment of neutrophils, and ROS generation from infiltrated neutrophils in the later phase. However, MMP-9 induction does not seem to be related to increased neutrophil infiltration in the later phase because SP600125 increased MMP-9 gene expression and its activity prior to the boosting of neutrophil infiltration by SP600125 in the later phase.

Definitive explanations for the different JNK inhibition effects observed in our study compared with the results of Uehara et al. (2005) cannot be provided. However, different dosing schedules may have caused the differing results found in the two studies. Even though JNK inhibitors in both of these studies selectively inhibited JNK activity (Bennett et al., 2001; Uehara et al., 2004), the selectivity may only be guaranteed within a certain range of blood concentrations. In contrast to our dosing regimen, Uehara et al., (2005) administered an intravenous bolus of JNK inhibitors to rats $15 \mathrm{~min}$ before ischemia and $4 \mathrm{~h}$ after reperfusion. In general, intraperitoneal and subcutaneous administration of drugs leads to lower, but more sustained blood concentrations than administration of an IV bolus. Therefore, the blood concentration profiles of the JNK inhibitors may be different, and higher concentrations caused by an IV bolus may inhibit other protein kinases, presumably resulting in protection against I/R injury to the liver.

Recently, Kim et al., (2005) proposed a termination mechanism for the innate immune response. They demonstrated that JNK negatively regulates NF-KBdependent gene expression by mediating the binding of AP-1 to the NF-kB promoter and subsequently recruiting histone deacetylase and modifying the active histone acetylase content. MIP- $1 \alpha$, MIP- $1 \beta$, MIP-2, and MMP-9 induced by SP600125 $8 \mathrm{~h}$ after reperfusion are expressed in a NF- $\kappa$ B-dependent manner (Haeberle et al., 2004; Lu et al., 2005). Therefore, it seems probable that sustained inhibition of JNK activity interferes with the gene expression termination process of these genes. However, it is not known whether this termination mechanism functions in hepatic $I / R$ injury because there is a dearth of detailed topological and chronological information regarding the interaction between the JNK/AP-1 and the NF-KB pathways in liver parenchymal and infiltrating inflammatory cells under I/R. A recent report (Kaiser et al., 2005) also summarizes the complicated roles of JNK. While cardiac I/R injury was reduced in jnk knockout mice and in mice expressing dominant negative JNK1/2 within the cardiac muscle, the injury was inhibited in transgenic mice expressing MKK7, a kinase upstream of JNK. Therefore, due to the complexity of the roles of JNK in $\mathrm{I} / \mathrm{R}$ injury, it is not easy to conclude that JNK inhibition protects the liver against I/R injury. Finally, further studies using various dosing regimens and 
A

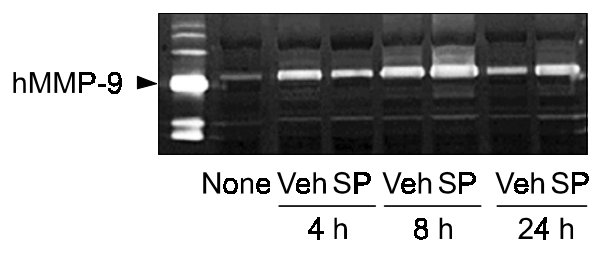

B

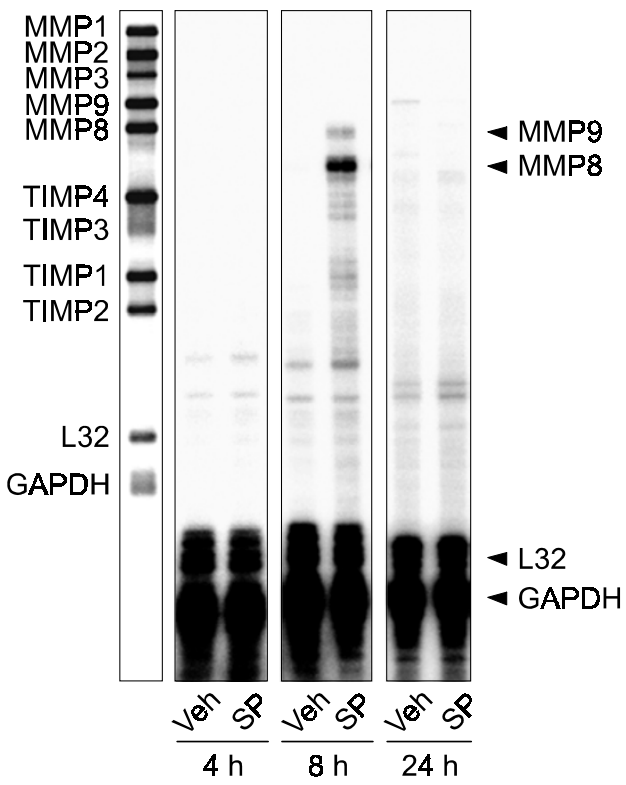

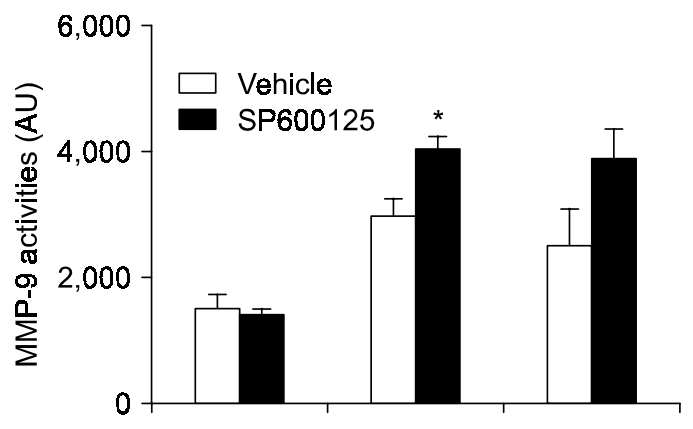
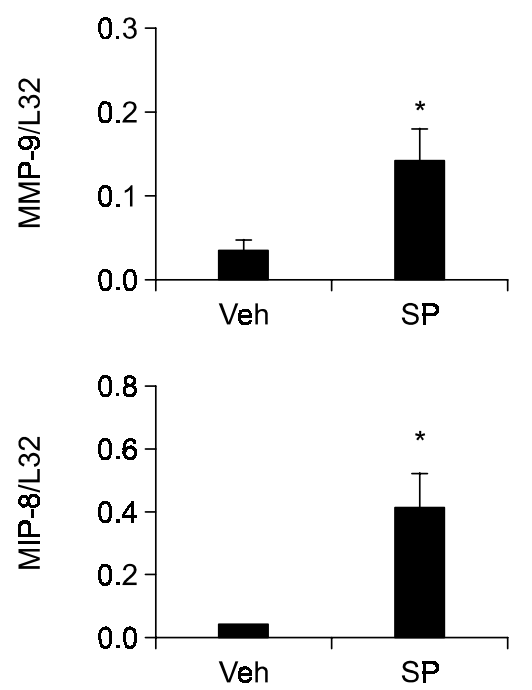

Figure 6. SP600125 increases the induction of matrix metalloproteinase-9 (MMP-9) in reperfused liver tissue. (A) Effect of SP600125 on MMP-9 gelatinolytic activity. At 4, 8, and $24 \mathrm{~h}$ after reperfusion, the gelatinase activity in $100 \mu \mathrm{g}$ of liver protein was determined by gelatin zymography. Gelatinolytic activities in arbitrary U (AU) are expressed as mean $\pm \mathrm{SE}(n=6)$, and an asterisk $\left(^{*}\right)$ indicates a statistical difference between the vehicle-treated and SP600125-treated I/R groups $(P<0.05)$. (B) Effect of SP600125 on MMP gene expression. RPA was performed with multiple MMP probes and total RNAs were obtained 4, 8, and $24 \mathrm{~h}$ after reperfusion. Veh and SP indicate the vehicle-treated and SP600125- treated groups, respectively. Relative band intensities of MMP-9 or MMP-8 to L32 were quantified and data are expressed as mean \pm SE $(n=6)$. An asterisk (*) indicates a statistical difference between the vehicle-treated and SP600125-treated I/R groups $(P<0.05)$.

clear pharmacokinetic data are needed in order to advance the investigation of the therapeutic application of JNK inhibitors in hepatic I/R injury.

\section{Acknowledgement}

This work was supported by the Korea Research Foundation Grant funded by the Korean Government (MOEHRD, R05-2003-000-11342-0).

\section{Reference}

Arndt PG, Suzuki N, Avdi NJ, Malcolm KC, Worthen GS. Lipopolysaccharide-induced c-Jun $\mathrm{NH}_{2}$-terminal kinase acti- vation in human neutrophils: role of phosphatidylinositol 3-kinase and Syk-mediated pathways. J Biol Chem 2004;279: 10883-91

Bennett BL, Sasaki DT, Murray BW, O'Leary EC, Sakata ST, Xu W. SP600125, an anthrapyrazolone inhibitor of Jun N-terminal kinase. Proc Natl Acad Sci USA 2001;98:13681-6

Bradham CA, Stachlewitz RF, Gao W, Qian T, Jayadev S, Jenkins $G$. Reperfusion after liver transplantation in rats differentially activates the mitogen-activated protein kinases. Hepatology 1997;25:1128-35

Cursio R, Mari B, Louis K, Rostagno P, Saint-Paul MC, Giudicelli J. Rat liver injury following normothermic ischemia is prevented by a phosphinic matrix metalloproteinase inhibitor. FASEB J 2001;16:93-5 


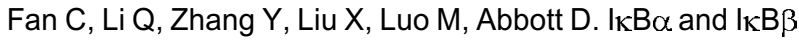
possess injury context-specific functions that uniquely influence hepatic NF- $\mathrm{kB}$ induction and inflammation. J Clin Invest 2004; 113:746-55

Fernandez L, Grande L, Gomez G, Rimola A, Marco A, Gelpi $E$. Preconditioning protects liver and lung damage in rat liver transplantation: role of xanthine/xanthine oxidase. Hepatology $2002 ; 36: 562-72$

Finch A, Davis W, Carter WG, Saklatvala J. Analysis of mitogen-activated protein kinase pathways used by interleukin 1 in tissues in vivo: activation of hepatic c-Jun N-terminal kinases 1 and 2, and mitogen-activated protein kinase kinases 4 and 7. Biochem J 2001;353:275-81

Gao Y, Signore AP, Yin W, Cao G, Yin XM, Sun F. Neuroprotection against focal ischemic brain injury by inhibition of c-Jun $\mathrm{N}$-terminal kinase and attenuation of the mitochondrial apoptosis-signaling pathway. J Cereb Blood Flow Metab 2005;25: 694-712

Haeberle HA, Casola A, Gatalica Z, Petronella S, Dieterich HJ, Ernst PB. I $\mathrm{KB}$ Kinase is a critical regulator of chemokine expression and lung inflammation in respiratory syncytial virus infection. J Virol 2004;78:2232-41

Ishii M, Suzuki Y, Takeshita K, Miyao N, Kudo H, Hiraoka R. Inhibition of c-Jun $\mathrm{NH}_{2}$-terminal kinase activity improves ischemia/reperfusion injury in rat lungs. J Immunol 2004;172: 2569-77

Jaeschke H, Lemasters JJ. Apoptosis versus oncotic necrosis in hepatic ischemia/reperfusion injury. Gastroenterology 2003a; $125: 1246-57$

Jaeschke $\mathrm{H}$. Molecular mechanisms of hepatic ischemia-reperfusion injury and preconditioning. Am J Physiol Gastrointest Liver Physiol 2003b;284:G15-26

Kaiser RA, Liang Q, Bueno O, Huang Y, Lackey T, Klevitsky R. Genetic inhibition or activation of JNK1/2 protects the myocardium from ischemia-reperfusion-induced cell death in vivo. J Biol Chem 2005;280:32602-8

Kato A, Gabay C, Okaya T, Lentsch AB. Specific role of interleukin-1 in hepatic neutrophil recruitment after ischemia/reperfusion. Am J Pathol 2002;161:1797-803

Kim T, Yoon J, Cho H, Lee WB, Kim J, Song YH. Downregulation of lipopolysaccharide response in Drosophila by negative crosstalk between the AP1 and NF-kB signaling modules. Nat Immunol 2005;6:211-8

Kobayashi M, Takeyoshi I, Yoshinari D, Matsumoto K, Morishita Y. P38 mitogen-activated protein kinase inhibition attenuates ischemia-reperfusion injury of the rat liver. Surgery 2002;131:344-9

Liedtke C, Plumpe J, Kubicka S, Bradham CA, Manns MP, Brenner DA, Trautwein C. Jun kinase modulates tumor necrosis factor-dependent apoptosis in liver cells. Hepatology 2002;36:315-25

Lu Y, Wahl LM. Production of matrix metalloproteinase-9 by activated human monocytes involves a phosphatidylinositol-3 kinase/Akt/IKKo/NF-kB pathway. J Leukoc Biol 2005;78: 259-65
Marderstein EL, Bucher B, Guo Z, Feng X, Reid K, Geller DA. Protection of rat hepatocytes from apoptosis by inhibition of c-Jun N-terminal kinase. Surgery 2003;134:280-4

Matsumura F, Yamaguchi Y, Goto M, Ichiguchi O, Akizuki E, Matsuda T. Xanthine oxidase inhibition attenuates Kupffer cell production of neutrophil chemoattractant following ischemia-reperfusion in rat liver. Hepatology 1998;28:1578-87

Mendelson KG, Contois LR, Tevosian SG, Davis RJ, Paulson $\mathrm{KE}$. Independent regulation of JNK/p38 mitogen-activated protein kinases by metabolic oxidative stress in the liver. Proc Natl Acad Sci USA 1996;93:12908-13

Miho N, Ishida T, Kuwaba N, Ishida M, Shimote-Abe K, Tabuchi $\mathrm{K}$. Role of the JNK pathway in thrombin-induced ICAM-1 expression in endothelial cells. Cardiovasc Res 2005;68:289-98

Onishi I, Tani T, Hashimoto T, Shimizu K, Yagi M, Yamamoto $\mathrm{K}$, Yoshioka K. Activation of c-Jun N-terminal kinase during ischemia and reperfusion in mouse liver. FEBS Lett 1997;420: 201-4

Paik YH, Schwabe RF, Bataller R, Russo MP, Jobin C, Brenner DA. Toll-Like receptor 4 mediates inflammatory signaling by bacterial lipopolysaccharide in human hepatic stellate cells. Hepatology 2003;37:1043-55

Schaur RJ, Dussing G, Kink E, Schauenstein E, Posch W, Kukovetz E, Egger G. The lipid peroxidation product 4-hydroxynonenal is formed by--and is able to attract--rat neutrophils in vivo. Free Radic Res 1994;20:365-73

Schierwagen C, Bylund-Fellenius AC, Lundberg C. Improved method for quantification of tissue PMN accumulation measured by myeloperoxidase activity. J Pharmacol Methods 1990; 23:179-86

Shin M, Yan C, Boyd D. An inhibitor of C-jun aminoterminal kinase (SP600125) represses c-Jun activation, DNA-binding and PMA-inducible 92-kDa type IV collagenase expression. Biochim Biophys Acta 2002;1589:311-6

Takeuchi D, Kato A, Ito H, Kimura F, Shimizu H, Ohtsuka M. Interleukin 18 causes hepatic ischemia/reperfusion injury by suppressing anti-inflammatory cytokine expression in mice. Hepatology 2004;39:699-710

Teoh N, Field J, Sutton J, Farrell G. Dual role of tumor necrosis factor- $\alpha$ in hepatic ischemia-reperfusion injury: studies in tumor necrosis factor- $\alpha$ gene knockout mice. Hepatology 2004;39:412-21

Uehara T, Bennett B, Sakata ST, Satoh Y, Bilter GK, Westwick JK, Brenner DA. JNK mediates hepatic ischemia reperfusion injury. J Hepatol 2005;42:850-9

Uehara T, Xi Peng X, Bennett B, Satoh Y, Friedman G, Currin R. c-Jun N-terminal kinase mediates hepatic injury after rat liver transplantation. Transplantation 2004;78:324-32

Zhai Y, Shen XD, O'Connell R, Gao F, Lassman C, Busuttil RW, Cheng G, Kupiec-Weglinski JW. Cutting edge: TLR4 activation mediates liver ischemia/reperfusion inflammatory response via IFN regulatory factor 3-dependent MyD88-independent pathway. J Immunol 2004;173:7115-9 
Zhao K, Zhao GM, Wu D, Soong Y, Birk AV, Schiller PW, Szeto $\mathrm{HH}$. Cell-permeable peptide antioxidants targeted to inner mitochondrial membrane inhibit mitochondrial swelling, oxidative cell death, and reperfusion injury. J Biol Chem 2004;279: 34682-90
Zwacka RM, Zhang Y, Zhou W, Halldorson J, Engelhardt JF. Ischemia/reperfusion injury in the liver of BALB/c mice activates $A P-1$ and nuclear factor- $\kappa B$ independently of $1 \kappa B$ degradation. Hepatology 1998;28:1022-30 